\title{
Long-term outcome of vaginal mesh or native tissue in recurrent prolapse: a randomized controlled trial
}

\author{
Alfredo L. Milani ${ }^{1}$ - Anne Damoiseaux ${ }^{2}$. Joanna IntHout ${ }^{3} \cdot$ Kirsten B. Kluivers $^{4}$. \\ Mariella I. J. Withagen ${ }^{5}$
}

Received: 28 August 2017 / Accepted: 5 November 2017 / Published online: 22 November 2017

(C) The Author(s) 2017. This article is an open access publication

\begin{abstract}
Introduction and hypothesis Our aim was to evaluate clinically relevant long-term outcomes of transvaginal mesh or native tissue repair in women with recurrent pelvic organ prolapse (POP).

Methods We performed a 7-year follow-up of a randomized controlled trial on trocar-guided mesh placement or native tissue repair in women with recurrent POP. Primary outcome was composite success, defined as absence of POP beyond the hymen, absence of bulge symptoms, and absence of retreatment for POP. Secondary outcomes were adverse events, pain, and dyspareunia. Multiple imputation was used for missing data of composite success and pain; estimates are presented with $95 \%$ confidence intervals (CI).
\end{abstract}

Preliminary data were presented at the 40th annual scientific meeting of the International Urogynecological Association in Nice, France, 11 June 2015.

Alfredo L. Milani

fredmilani@me.com

1 Department of Obstetrics \& Gynecology, Reinier de Graaf Hospital, P.O. Box 5011, 2600, GA Delft, The Netherlands

2 Department of Obstetrics \& Gynecology, Catharina Hospital, P.O. Box 1350, 5602, ZA Eindhoven, The Netherlands

3 Department for Health Evidence (133), Radboud Institute for Health Sciences, Radboud University Medical Center, P.O. Box 9101, 6500, HB Nijmegen, The Netherlands

4 Department of Obstetrics \& Gynecology (791), Radboud University Medical Center, P.O. Box 9101, 6500, HB

Nijmegen, The Netherlands

5 Department of Obstetrics \& Gynecology, University Medical Center Utrecht, Heidelberglaan 100 P.O. Box 85500, Room F05.126,

Utrecht, The Netherlands
Results Between August 2006 and July 2008, 194 women were randomized; 190 underwent surgery. At 7 years, 142 (75\%) were available for analysis, of whom, the primary outcome could be calculated in 127. Composite success was $53 \%(95 \%$ CI 41,66$)$ for mesh and $54 \%(95 \%$ CI 42 , 65 ) for native tissue. Repeat surgery for POP was $25 \%$ for mesh and $16 \%$ for native tissue (difference 9\%; 95\% CI $-5,23)$ and occurred in untreated compartments in the mesh group and treated compartments in the native tissue group. Mesh exposure rate was $42 \%$; pain with mesh $39 \%$ and native tissue $50 \%$ (difference $-11 \%, 95 \% \mathrm{CI}-27,6$ ); dyspareunia with mesh $20 \%$ and native tissue $17 \%$ (difference $3 \%, 95 \%$ CI $-9,17)$.

Conclusions Seven-year composite success rates appeared similar for mesh and native tissue. Mesh did not reduce long-term repeat surgery rates due to de novo POP in nonmesh-treated vaginal compartments. Mesh exposure rates were high, though significant differences in pain and dyspareunia were not detected.

Clinical trial registration. ClinicalTrials.gov, NCT00372190.

Keywords Long-term outcome $\cdot$ Mesh $\cdot$ Native tissue $\cdot$ Pain $\cdot$ Pelvic organ prolapse $\cdot$ Surgery

\section{Introduction}

The 10-year rate of repeat surgery for pelvic organ prolapse (POP) and urinary incontinence (UI) is as high as $17 \%$ [1]. Searching for more effective treatments and inspired by favorable results of synthetic mesh use in inguinal hernia and stress urinary incontinence (SUI) surgery, mesh was introduced in vaginal POP surgery [2-4]. The commercial introduction of the relatively easy to use mesh 
kit in 2005 has accelerated worldwide use of synthetic mesh, while 1-year outcomes of the first prospective observational study were first published in 2007 [5]. An increasing number of adverse events, including mesh exposure, pain, and dyspareunia led to the US Food and Drug Association (FDA) Public Health Notifications of 2008 and 2011, with the intention to increase public awareness of risks associated with surgical mesh for transvaginal repair of POP [6]. Subsequent class action lawsuits occurred and gradually led to removal of many vaginal mesh products from the market.

A limited number of randomized clinical trials (RCT) compared short-term safety and efficacy of nonabsorbable mesh with native tissue repair [7]. Long-term data of those trials are lacking, though sorely needed. This RCT focused on patients with recurrent POP and compared a trocar-guided nonabsorbable tension-free vaginal mesh (TVM) with native tissue repair [8]. At 12 months, anatomic failures after TVM appeared fewer than native tissue repair, but symptom decrease and quality of life (QoL) improvement were similar between groups [8].

The study reported focused on the long-term follow-up of that RCT, with the primary aim being comparison of long-term composite success (a combination of anatomy, functional success, and absence of retreatment) 7 years after surgery. The secondary aim was to describe longterm adverse events, with particular focus on pain and dyspareunia.

\section{Materials and methods}

The original trial was performed in 13 centers in The Netherlands between August 2006 and July 2008 (www.clinicaltrials.gov, NCT00372190). Patients with recurrent POP were 1:1 randomized between a firstgeneration nonabsorbable TVM (anterior, posterior or total) (Prolift ${ }^{\mathrm{TM}}$, Ethicon, Somerville, NJ, USA) and conventional vaginal native tissue repair. Repairs comprised anterior or posterior colporrhaphies; a Manchester Fothergill procedure; or vaginal hysterectomy with high uterosacral ligament suspension, sacrospinous ligament suspension, or a combination. Details regarding design, randomization, sample size, surgical interventions, and 1-year outcomes have previously been published [8]. Extended follow-up at 7 and 10 years was approved by the Medical Ethics Committee, region Arnhem-Nijmegen, The Netherlands, on 28 April 2014 under no. NL46834. 091.14 and registered in clinicalTrials.gov, NCT00372190. Informed consent was obtained prior to inclusion in the extended follow-up.

All participants of the index study received a letter to inform them on the intended long-term follow-up. Two weeks later, a research nurse approached those women by telephone and scheduled an outpatient clinic appointment if they agreed to participate. One independent examiner (AD), a subspecialist in urogynecology, was blinded to the index procedures and performed all interviews and physical examinations at the original study sites. Participants completed the same validated urogynecologic questionnaires as were used at baseline and 1 year in the index study: Global Impression of Improvement questionnaire (PGI-I), visual analog scale (VAS), EuroQol-5D (EQ-5D), Urogenital Distress Inventory (UDI), Defecatory Distress Inventory (DDI), Incontinence Impact Questionnaire (IIQ), and the short form of the Pelvic Organ Prolapse Urinary Incontinence Sexual Questionnaire (PISQ-12) [9-12]. The UDI, DDI, and IIQ are each subdivided into five domains, with subscales ranging from 0 to 100 and higher scores indicating more bother and worse QoL. Scores on 12 individual questions of the PISQ-12 ranged from 0 to 4 on a 5-point Likert scale, and total scores range from 0 (poorest) to 48 (best) for sexual function [13].

Subjective prolapse symptoms were considered present if a patient answered affirmatively to the question: Do you see or do you feel a vaginal bulge? Pain was considered present if a patient answered affirmatively to the question: Do you experience pain in the lower abdomen or genital region? Dyspareunia was considered present if a patient answered affirmatively to the question: Do you experience pain during intercourse? The degree of bother caused by dyspareunia was registered using a 4-point Likert scale (1, not at all bothered; 4 bothered quite a bit). SUI was considered present if a patient answered affirmatively to the question: Do you experience involuntary urine loss during physical exercise, coughing, or sneezing? De novo SUI was considered present if the participant had no SUI according the baseline questionnaire but answered affirmatively at 7 years or had received treatment for SUI after the trial's index surgery within the 7-year followup.

Pain was assessed with a 10-point VAS, where 0 denoted no pain and 10 the worst imaginable. Prior to physical examination, women were requested to undergo two VAS for pain: one at rest and one during physical activity.

Physical examination consisted of POP staging using the Pelvic Organ Prolapse Quantification (POP-Q) system [14]. A thorough examination of the vagina was performed to objectify any visible or palpable mesh exposure, prominence, or excessive scarring of the vaginal epithelium and pain during vaginal examination [15]. Participants were asked to rate pain intensity during vaginal examination on another VAS. The examiner also completed a VAS of subjective impression she had of pain experienced by the patient, blinded to the patient's score, 
and was not informed on this specific assessment prior to the examination.

In contrast with the primary outcome at 1 year, defined as an anatomic failure in treated vaginal compartments, the primary outcome of the study reported here was composite success, defined as a combination of absence of POP beyond the hymen in a treated or nontreated compartment, absence of bulge symptoms, and absence of retreatment for POP in a treated or nontreated compartment [16]. If no POP beyond the hymen was noted on POP-Q examination but the questionnaire was missing, a composite outcome could not be calculated. This also applied if the questionnaire noted absence of bulge symptoms, but the POP-Q was missing. If, however, the questionnaire noted bulge symptoms, but the POP-Q was missing, the composite outcome was considered a failure, as was POP beyond the hymen without a questionnaire. Any registered retreatment for POP, with or without follow-up, was considered a failure. Retrospectively, composite success rates were calculated for all participants at the 1-year follow-up and used for comparison over time.

Secondary outcomes were anatomic recurrences overall and failures per treated vaginal compartment at 7 years, defined as POP stage $\geq$ II, POP $>$ hymen, de novo SUI, surgery-related complications for mesh, pain perception, and dyspareunia. Descriptive statistics with numbers, percentages, and risk differences with 95\% CI were used to summarize baseline characteristics and primary and secondary outcomes. The 95\% CI for differences between median values was estimated with the Hodges-Lehmann estimator [17].

To account for missing data of women who were alive but did not attend the 7-year follow-up visit, a multiple imputation approach was used for composite success and UDI domain of pain. Analyses were performed using the combination of 50 data sets generated with the fully conditional method (chained equations) for imputation of missing values. Values imputed for pain $<0$ or $>100$ were truncated to 0 or 100 , and composite success was imputed as a binary variable. Missing data of women who died during the 7-year follow-up were not imputed in the main analysis, but were imputed as failures in a sensitivity analysis of composite success. After multiple imputation, composite success was analyzed using a binomial distribution, an identity link, and covariate treatment group. UDI domain pain was analyzed using a linear model, with covariate treatment group and pain at baseline.

Analysis was according the intention-to-treat principle. Statistical analyses were performed using SPSS Statistics for Windows, version 22.0 and analyses of pain and composite success with the STAT package (SAS ${ }^{\circledR}$ statistical software, version 9.4, SAS Institute Inc., Cary, NC, USA).

\section{Results}

One hundred and ninety-four women were randomized in the index trial between August 2006 and July 2008, of whom 190 underwent surgical treatment. In this 7-year follow-up, $142(75 \%)$ women were available for analysis (Fig. 1). Based on the selection criteria described in the Materials and Methods section, a composite outcome could be calculated of 127 participants. Of 15 women data were incomplete, so a composite outcome could not be calculated.

Characteristics of participants in the 7-year follow-up were similar between groups at baseline (Table 1), including post hoc calculated composite success rates at 1 year (76\%, $95 \%$ CI 62,85 vs. $74 \%, 95 \%$ CI 62,84 for mesh and native tissue, respectively). Some differences existed between responders and nonresponders in the study reported here: responders were significantly younger and had lower POP stages at the time of index surgery and more often had reported dyspareunia at baseline. General health scores (VAS, EQ-5D) at 1-year were higher among responders (Table 2).

The primary outcome, overall composite success at 7 years, was similar between women treated with mesh or native tissue $(53 \%$; $95 \%$ CI 41,66 vs. $54 \%$; $95 \%$ CI 42, 65; Table 3). These results were similar to the percentages estimated after applying multiple imputations for missing data. Success rates were slightly lower after imputing failures for missing data of deceased patients, but the difference between groups remained negligible. Between 1 and 7 years, composite success rates decreased by $22 \%$ for mesh and $20 \%$ for native tissue (Table 3).

Repeat surgery rates for POP were somewhat different between groups (Table 3 ). In the mesh group, repeat surgery was performed in $14 / 56$ cases. Nine times an additional mesh was inserted (8 vaginally and 1 abdominally), and in 13 cases, surgery was in the non-mesh-treated compartment. In contrast, repeat surgery in the native tissue group occurred in 11/69 cases, and more frequently in the treated vaginal compartment. Nine times a mesh was inserted in this group ( 8 vaginally and 1 abdominally). In the mesh group, there were fewer anatomic failures (POP $\geq$ II) in the treated anterior vaginal compartment compared with in the native tissue group. Bulge symptoms and patient global impressions of improvement were not significantly different between groups (Table 7 , "Appendix 3").

At 7 years, there was no significant difference between groups in terms of de novo SUI (19\% mesh, $12 \%$ native tissue) (Table 8 "Appendix 4"). The cumulative prevalence of mesh exposure at 7 years was $42 \%$ in the mesh group, with $13 \%$ repeat surgeries for mesh exposure in this 7 - 


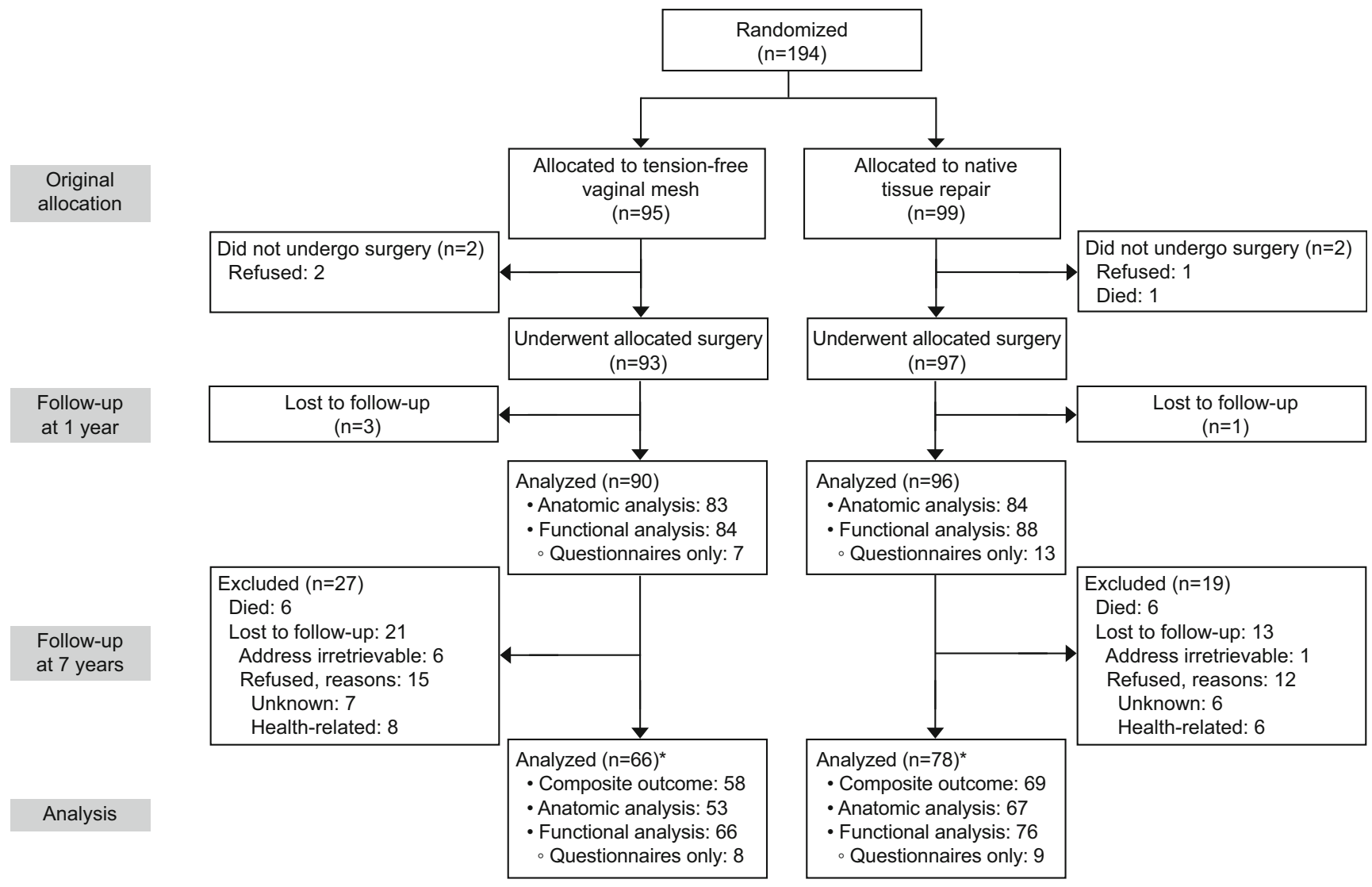

Fig. 1 Consolidated Standards of Reporting Trials (CONSORT) flowchart of randomization and follow-up. *Includes those lost to follow-up at 1 year

year period (Table 8, "Appendix 4"). Ten patients (45\%) with exposure experienced no symptoms; 12 patients (55\%) reported pain. In 77\% (17 patients), exposure was $<1 \mathrm{~cm}$ (Addendum, Table 5, "Appendix 1"). In the native tissue group, four patients $(6 \%)$ had exposure: two due to mesh placement after the index surgery, one due to a Prolene suture used for sacrospinous ligament fixation and one after midurethral sling inserted after index surgery.

Data on pain and dyspareunia assessed by interview, self-completed questionnaires, and during gynecological examinations are shown in Table 8, "Appendix 4". Estimates of patient self-reported pain scores (UDI) with and without multiple imputation were not significantly different between groups (Table 4). Per-protocol analysis did not reveal a significant difference either between mesh or native tissue repair (Table 4). Provoked pain during gynecological examination, however, was significantly more prevalent in the mesh group (Table 8, "Appendix $4 ")$.

Changes in health-related QoL scores between baseline and 7 years are shown in Table 6, "Appendix 2"; neither group showed significant changes over time in sexual function measured with the PISQ-12.

\section{Discussion}

The long-term follow-up of this multicenter RCT showed similar composite success rates 7 years after TVM or native tissue repair in women with recurrent POP. Women treated with mesh often developed POP in a non-meshtreated vaginal compartment with the need for repeat surgery. In contrast, after native tissue repair, significantly more recurrences were seen in the treated compartments. This phenomenon has been reported for the 1-year followup $[18,19]$.

Compared with a composite success of $84 \%$ at 5 -year follow-up in a French cohort study using the same mesh kit, composite success of $53 \%$ in our mesh group was considerably lower [20]. In the French study, all patients received total vaginal mesh that treated all three vaginal compartments. Subanalysis of total mesh implantations in our study showed a composite success rate of $73 \%$ at 7 years, comparable with French results. One should consider, however, that total vaginal mesh implants are associated with a significantly higher risk of mesh exposure [21]. A remarkable finding in our study was the significant decrease between post hoc calculated composite success rates at 1 year and composite success rates at 7 years 
Table 1 Characteristics of responders (participants in the 7year follow-up) by treatment group

\begin{tabular}{|c|c|c|c|}
\hline & $\operatorname{Mesh}(n=58)$ & $\begin{array}{l}\text { Native tissue } \\
(n=69)\end{array}$ & $\begin{array}{l}\text { Difference } \\
(95 \% \mathrm{CI})\end{array}$ \\
\hline Age at time of surgery (years) & $60.9 \pm 9.0$ & $62.4 \pm 10.2$ & $-1.5(-5.1,1.7)$ \\
\hline Age at follow-up (years) & $67.1 \pm 8.9$ & $68.8 \pm 9.9$ & $-1.7(-5.1,1.7)$ \\
\hline Follow-up (months) & $84(65-98)$ & $84(65-99)$ & $0(-3.0,3.0)$ \\
\hline Parity $(n)$ & $2(1-6)$ & $2(1-5)$ & $0(0,0)$ \\
\hline BMI $\left(\mathrm{kg} / \mathrm{m}^{2}\right)$ & $26.4 \pm 4.1$ & $26.8 \pm 4.3$ & $-0.4(-2.0,1.1)$ \\
\hline Prior number of POP surgeries & $1(1-3)$ & $1(1-3)$ & $0(0,0)$ \\
\hline $\begin{array}{l}\text { Prior number of treated vaginal } \\
\text { compartments }\end{array}$ & $2(1-3)$ & $2(1-3)$ & $0(0,0)$ \\
\hline \multicolumn{4}{|l|}{ POP-Q stage at time of surgery } \\
\hline - Stage II & $33(57)$ & $36(52)$ & $5(-13,22)$ \\
\hline - Stage III & $24(41)$ & $31(45)$ & $-4(-21,14)$ \\
\hline - Stage IV & $1(2)$ & $2(3)$ & $-1(-6,4)$ \\
\hline \multicolumn{4}{|l|}{ Pain at baseline } \\
\hline - Yes & $26 / 55(47)$ & $35 / 58(60)$ & $-13(-31,5)$ \\
\hline - UDI pain score & $26.1(24.2,28.0)$ & $28.8(26.3,31.3)$ & $\begin{array}{l}-2.6(-10.9 \\
5.6)\end{array}$ \\
\hline \multicolumn{4}{|l|}{ Dyspareunia at baseline } \\
\hline - Moderate to quite a bit & $11 / 53(21)$ & $15 / 58(26)$ & $-5(-21,11)$ \\
\hline - Yes & $18 / 53(34)$ & $27 / 58(46)$ & $-12(-31,6)$ \\
\hline \multicolumn{4}{|l|}{ Composite success and pain score at 1 year } \\
\hline - Composite success; $n$ [\%: $(95 \% \mathrm{CI})]$ & $40 / 53[76:(62,85)]$ & $43 / 58[74:(62,84)]$ & $2(-15,18)$ \\
\hline - UDI Pain score; $n(\mathrm{CI})$ & $13.2(11.4,15.0)$ & $15.1(13.5,16.7)$ & $-1.8(-8.5,4.9)$ \\
\hline
\end{tabular}

Data presented as mean \pm standard deviation (SD), median (range), $n(\%), \mathrm{I}[\%$ : (95\% CI)], \% (95\% CI), or mean $(95 \% \mathrm{CI})$

$B M I$ body mass index, $P O P-Q$ Pelvic Organ Prolapse Quantification system, UDI pain score urodynamic pain score, $0-100, C I$ confidence interval in both treatment groups. Increasing failure rates have also been reported 7 years after abdominal sacrocolpopexy [22].

For the long-term follow-up, we used a primary outcome different from that used in the index study. Barber et al. demonstrated in 2009 that patient impression of improvement was associated with absence of vaginal bulge symptoms [16]. The use of a composite outcome (combining anatomic and functional success, in the absence of retreatment) is therefore considered clinically more relevant and is in accordance with International Urogynecological Association and International Continence Society (IUGA-ICS) recommendations [16, 23].

The mesh exposure rate increased substantially over time, from $17 \%$ at 1 year to $42 \%$ at 7 years [8] There are a number of possible explanations. The mesh kit used consisted of relatively large pieces of nonabsorbable mesh (anterior $10 \times 13 \mathrm{~cm}$, posterior $7 \times 16 \mathrm{~cm}$ ) with relatively high weight of $45 \mathrm{~g} / \mathrm{m}^{2}$. The total amount and weight of implanted mesh are correlated with the risk of exposure
[21, 24-26]. Furthermore, 22 surgeons performed index surgeries, and although they were all considered experienced, they had their own learning curves and levels of experience [21]. An increase in exposure rates over the years has also been described in the extended follow-up of abdominal sacrocolpopexy [22].

In the media and according to lawsuits, there are numerous reports of patients with chronic pelvic pain and dyspareunia after mesh insertion [27]. We used various tools to assess pain and dyspareunia: patient selfcompleted questionnaires, doctor interviews, and VAS scores. We observed nonsignificant differences in ratings of pain and dyspareunia between groups. We hypothesize that repeat POP surgery itself may cause pain, and pain may not be solely caused by the mesh.

Change in primary outcome is a limitation of this study, since the index study was powered on anatomic success and not on subjective outcomes, which probably would have needed a larger sample size. Loss of participants in long-term follow-up studies is inevitable, particularly when considering the advanced mean age of the 
Table 2 Characteristics of responders versus nonresponders (women lost to follow-up)

\begin{tabular}{|c|c|c|c|}
\hline & $\begin{array}{l}\text { Responders } \\
(n 127)\end{array}$ & $\begin{array}{l}\text { Lost to follow-up } \\
\text { (n 63) }\end{array}$ & $\begin{array}{l}\text { Difference } \\
(95 \% \mathrm{CI})\end{array}$ \\
\hline Age at time of surgery (years) & $61.6 \pm 9.7$ & $67.7 \pm 10.4$ & $-6.1 *(-9.2,-3.1)$ \\
\hline Parity & $2(1-6)$ & $3(0-5)$ & $0(0,1.0)$ \\
\hline BMI $\left(\mathrm{kg} / \mathrm{m}^{2}\right)$ & $26.6 \pm 4.2$ & $26.9 \pm 4.1$ & $-0.3(-1.6,1.1)$ \\
\hline Prior number of POP surgeries & $1(1-3)$ & $1(1-2)$ & $0(0,0)$ \\
\hline Prior number of treated vaginal compartments & $2(1-3)$ & $2(1-3)$ & $0(0,0)$ \\
\hline \multicolumn{4}{|l|}{ POP-Q stage at time of surgery } \\
\hline - Stage II & $69(54.3)$ & $21(33.3)$ & $21.0 *(6.5,35.5)$ \\
\hline - Stage III & $55(43.3)$ & $42(66.7)$ & $-23.4 *(-37.8,-8.9)$ \\
\hline - Stage IV & $3(2.4)$ & 0 & $2.4(-0.3,5.0)$ \\
\hline \multicolumn{4}{|l|}{ Pain at baseline } \\
\hline - Yes & $61 / 113(54.0)$ & $23 / 48(47.9)$ & $6.1(-10.8,22.9)$ \\
\hline - UDI pain score & $28.7(26.9,30.4)$ & $23.4(19.8,27.0)$ & $5.3(-3.7,14.3)$ \\
\hline \multicolumn{4}{|l|}{ Dyspareunia at baseline } \\
\hline - Moderately to quite a bit & 26/111 (23.4) & $3 / 45(6.7)$ & $16.8 *(6.0,27.5)$ \\
\hline - Yes & $45 / 111(40.5)$ & $4 / 45(8.9)$ & $31.7 *(19.3,44.0)$ \\
\hline \multicolumn{4}{|l|}{ Outcomes at 1-year follow-up } \\
\hline Composite success & $83 / 111(74.8)$ & $31 / 43(72.1)$ & $2.6(-12.9,18.3)$ \\
\hline Overall POP-Q $\geq$ stage II & $66 / 115(57.4)$ & $23 / 52(44.2)$ & $13.2(-3.1,29.4)$ \\
\hline PGI-I (much to very much better) & $78 / 108(72.2)$ & $31 / 49(63.3)$ & $8.9(-6.9,24.9)$ \\
\hline VAS EQ-5D & $78.2 \pm 14.6$ & $72.4 \pm 20.3$ & $5.8^{*}(0.2,11.5)$ \\
\hline Exposure & $9 / 114(7.9)$ & $5 / 52(9.6)$ & $-1.7(-11.1,7.7)$ \\
\hline UDI pain score & $14.3(13.1,15.5)$ & $13.8(10.4,17.1)$ & $0.5(-6.9,7.9)$ \\
\hline \multicolumn{4}{|l|}{ Dyspareunia } \\
\hline - Moderately to quite a bit & $18 / 115(16.2)$ & $3 / 47(4.7)$ & $9.3(-0.4,18.9)$ \\
\hline - Yes & $35 / 115(30.4)$ & $8 / 46(17.4)$ & $13.0(-0.8,26.9)$ \\
\hline
\end{tabular}

Data presented as mean \pm standard deviation (SD), median (range), $n(\%)$, or mean $(95 \% \mathrm{CI})$

$B M I$ body mass index, PGI-I Patient Global Impression of Improvement, VAS EQ-5D perceived health condition according visual analog scale, EuroQuol-5D questionnaire $(100=$ best imaginable, $0=$ worst imaginable $), U D I$ pain score urodynamic pain score, $0-100, C I$ confidence interval

*This difference would be statistically significant if tested at a significance level of 0.05 target group. Restricting the analysis to patients who completed the 7-year follow-up provides valid results if missing data are completely random; otherwise, it generates potentially biased results. Use of the multiple imputation technique, by which imputations of missing values are based on other known patient characteristics, leads to unbiased results with correct standard errors [28]. However, although this approach removes bias, it does not add power to the study. Data should therefore be interpreted with caution, since the study lacks power on negative outcomes. Furthermore, continuous negative media attention may have influenced the way participants responded to the questionnaires.

Although the mesh kit was withdrawn from the market in 2013, long-term data are still relevant to many patients, their doctors, and other stakeholders, e.g., health care inspectorates. According to sales information by Johnson \& Johnson, >220,000 mesh kits were sold worldwide, in addition to comparable kits sold by other companies.

Strengths of this study are the design (multicenter RCT), systematic long-term follow-up, physical exam by one independent observer (blinded to the index procedures), and the high response rate. Furthermore, the extensive assessment of pain and dyspareunia with data at both baseline and 7 years after index surgery is unique. The 2006 American College of Obstetricians and Gynecologists Committee Opinion on Ethical Guidelines in Innovative Practice state that: "without adequate data on risks and benefits of new treatments, patients are unable to provide truly informed consent" [29]. Our long-term evaluation may contribute to these guidelines and offer support when counseling patients with recurrent $\mathrm{POP}$, specifically regarding long-term risks of recurrence, pain, and dyspareunia following vaginal mesh kit surgery for POP. 
Table 3 Primary and secondary outcomes at 7 years

\begin{tabular}{|c|c|c|c|}
\hline & Mesh & Native tissue & $\begin{array}{l}\text { Risk difference } \\
(95 \% \mathrm{CI})\end{array}$ \\
\hline \multicolumn{4}{|l|}{ Primary outcome } \\
\hline \multicolumn{4}{|l|}{ Composite success overall } \\
\hline - Participants, $n$ [\% (95\% CI)] & $31 / 58[53(41,66)]$ & $37 / 69[54(42,65)]$ & $-1(-18,17)$ \\
\hline - Estimated \% (95\% CI) after MI ${ }^{\mathrm{a}}$ & $53(40,66)$ & $54(43,65)$ & $-1(-18,16)$ \\
\hline - Estimated \% (95\% CI) after MI ${ }^{\mathrm{b}}$ & $51(38,64)$ & $50(39,61)$ & $-1(-17,16)$ \\
\hline \multicolumn{4}{|l|}{ Change in composite success between 1 and 7 years } \\
\hline$\%(95 \% \mathrm{CI})$ of 7 -year participant data & $-22(-39,-5)$ & $-20(-37,-4)$ & $2(-12,16)$ \\
\hline Composite failures & $27 / 58(47)$ & $32 / 69(46)$ & $1(-17,18)$ \\
\hline - Failure in treated compartment & $3 / 58(5)$ & $18 / 69(26)$ & $-21 *(-33,-9)$ \\
\hline - Failure in untreated compartment & $17 / 58(29)$ & $5 / 69(7)$ & $22 *(9,35)$ \\
\hline - Failure due to bulge but no POP $>$ hymen & $5 / 58(9)$ & $1 / 69(1)$ & $7(-1,15)$ \\
\hline - Failure due to bulge (questionnaire only) & $2 / 58(3)$ & $8 / 69(12)$ & $-8(-17,1)$ \\
\hline \multicolumn{4}{|l|}{ Secondary outcomes } \\
\hline Reoperation for POP & $14^{\mathrm{c}} / 56(25)$ & $11^{\mathrm{d}} / 69(16)$ & $9(-5,23)$ \\
\hline - In treated compartment & $1(7)$ & $9(82)$ & $-75 *(-100,-48)$ \\
\hline - In nontreated compartment & $13(93)$ & $2(18)$ & $75^{*}(48,100)$ \\
\hline $\mathrm{POP} \geq$ stage II & $28 / 53(53)$ & $47 / 67(70)$ & $-17(-35,0)$ \\
\hline Reoperation for POP and/or POP-Q $\geq$ stage II & $35 / 56(62)$ & $53 / 69(77)$ & $-15(-30,2)$ \\
\hline POP > hymen & $8 / 53(15)$ & $12 / 67(18)$ & $-3(-16,10)$ \\
\hline POP $>$ hymen, no sensation of bulge & $4 / 53(8)$ & $7 / 67(10)$ & $-3(-13,7)$ \\
\hline Reoperation for POP and/or POP > hymen & $22 / 58(38)$ & $23 / 69(33)$ & $5(-12,21)$ \\
\hline \multicolumn{4}{|l|}{ Subjective outcomes } \\
\hline - Sensation of bulge & $14 / 66(21)$ & $17 / 76(22)$ & $-1(-14,19)$ \\
\hline - PGI-I (much to very much better) & $42 / 60(70)$ & $41 / 72(57)$ & $13(-3,29)$ \\
\hline
\end{tabular}

Data presented as $n(\%), n[\%(95 \% \mathrm{CI})]$, or $\%(95 \% \mathrm{CI})$

POP pelvic organ prolapse, $P G I-I$ Patient Global Impression of Improvement, $M I$ multiple imputation of missing data,

${ }^{\text {a }}$ MI excluding deceased patients

${ }^{\mathrm{b}}$ MI with failures for missings of deceased patients

${ }^{c}$ Nine patients received another mesh

${ }^{\mathrm{d}}$ Nine patients received mesh

*This difference would be statistically significant if tested at a significance level of 0.05
Findings in this study strengthen the necessity of long-term observations on safety and efficacy when surgical devices are used in POP surgery. In every woman with recurrent POP, a native tissue repair can be reconsidered, preferably based on a prediction model [30]. Only if native tissue repair is expected to be inferior should a smaller piece of lightweight vaginal

Table 4 Pain at 7 years

\begin{tabular}{llll}
\hline & Mesh & Native tissue & Risk difference (95\%CI) \\
\hline $\begin{array}{l}\text { Indicated on questionnaire } \\
\quad \text { (intention-to-treat analysis) }\end{array}$ & & & \\
Questionnaires $(n)$ & 66 & 72 & \\
Pain: yes & $26(39)$ & $36(50)$ & $-11(-27,6)$ \\
- UDI pain score & $16.2(16.2,16.2)$ & $20.2(18.6,21.8)$ & $-4.1(-11.3,3.1)$ \\
- Estimated pain score after MI & $17.8(13.0,22.6)$ & $18.9(14.6,23.3)$ & $-1.1(-7.5,5.2)$ \\
Having sexual intercourse & $30(46)$ & $30(42)$ & $4(-13,20)$ \\
Indicated on questionnaire & & & \\
$\quad$ per-protocol analysis) & 72 & 66 & \\
Questionnaires $(n)$ & $29(40)$ & $33(50)$ & $-10(-26,7)$ \\
Pain: yes & &
\end{tabular}

Data presented as $n(\%)$ or mean $(95 \% \mathrm{CI})$

MI multiple Imputation, UDI pain score Urogenital Distress Inventory, range 0-100, CI confidence interval At 7 years, 9 native tissue patients received mesh: 8 were transvaginal mesh (TVM), of whom 6 completed the questionnaire 
mesh or an abdominal mesh procedure be considered, but only if performed by experienced surgeons [31]. It is of utmost importance to counsel every woman planning to undergo any kind of POP surgery on the risks of pain and dyspareunia, particularly in case of repeat surgery.

Acknowledgements The authors thank Ms. Ada van der Ster, research coordinator at the Reinier de Graaf Hospital Delft, for her logistic support in contacting patients.

Funding Supported by an unrestricted educational grant from Ethicon Women's Health \& Urology to Radboud University Medical Center. Ethicon was not involved in study setup, design, data acquisition, data analysis, data interpretation, editing, or any other aspect of this study.

\section{Compliance with ethical standards}

Conflict of interest None.

\section{Appendix 1}

Table 5 Addendum. Classification of complications by category and grades of pain at clinical visit 7 years following surgery

\begin{tabular}{|c|c|c|c|c|c|c|}
\hline & & $\operatorname{Mesh}(n=53)$ & & Native tissue ( $r$ & & Risk difference $(95 \% \mathrm{CI})$ \\
\hline Any comp & & $40(75)$ & & $39(58)$ & & $17.3 \% *(0.7,33.8)$ \\
\hline Category & Grades of pain & Asymptomatic & Symptomatic & Asymptomatic & Symptomatic & \\
\hline & & $12(23)$ & $28(53)$ & $5(8)$ & $34(51)$ & \\
\hline 1 & & $2(4)$ & $16(30)$ & $2(3)$ & $33(49)$ & \\
\hline & $\mathrm{a}$ & 2 & & 2 & & \\
\hline & $\mathrm{b}$ & & 7 & & 5 & \\
\hline & $\mathrm{c}$ & & 6 & & 9 & \\
\hline & $\mathrm{d}$ & & 1 & & 2 & \\
\hline & e & & 2 & & 17 & \\
\hline 2 & & $8(15)$ & $9(17)$ & $2(3)$ & $1(2)$ & \\
\hline & a & 8 & & 2 & & \\
\hline & $\mathrm{b}$ & & 2 & & & \\
\hline & $\mathrm{c}$ & & 3 & & & \\
\hline & $\mathrm{d}$ & & & & & \\
\hline & $\mathrm{e}$ & & 4 & & 1 & \\
\hline 3 & & $2(4)$ & $3(6)$ & $1(2)$ & $0(0)$ & \\
\hline & $\mathrm{a}$ & 2 & & 1 & & \\
\hline & $\mathrm{b}$ & & 2 & & & \\
\hline & $\mathrm{c}$ & & 1 & & & \\
\hline & $\mathrm{d}$ & & & & & \\
\hline & $\mathrm{e}$ & & & & & \\
\hline
\end{tabular}

Data presented as numbers $(\%)$

Category: (1) Vaginal, no epithelial separation; includes prominence or excessive scarring, (2) vaginal epithelial separation $\leq 1 \mathrm{~cm}$, (3) vaginal epithelial separation $\geq 1 \mathrm{~cm}$

Grades of pain: (a) Asymptomatic or no pain, (b) provoked pain only (during vaginal examination), (c) pain during sexual intercourse, (d) pain during physical activities, (e) spontaneous pain

*This difference would be statistically significant if tested at a significance level of 0.05 


\section{Appendix 2}

Table 6 Changes in healthrelated quality of life and sexual function between baseline and 7 years

\begin{tabular}{|c|c|c|c|c|}
\hline & & $\operatorname{Mesh}(n$ 66) & Native tissue $(n 76)$ & Difference $(95 \% \mathrm{CI})$ \\
\hline \multicolumn{5}{|c|}{ Mean change in UDI domain scores } \\
\hline \multirow[t]{5}{*}{ UDI } & Overactive bladder & $-6.3 \pm 25.0$ & $-3.4 \pm 27.5$ & $2.9(-6.8,12.6)$ \\
\hline & Incontinence & $3.3 \pm 26.0$ & $1.3 \pm 27.0$ & $-2.0(-11.5,7.5)$ \\
\hline & Obstructive micturition & $-6.0 \pm 27.6$ & $-4.8 \pm 29.9$ & $1.2(-9.0,11.5)$ \\
\hline & Pain & $-7.8 \pm 24.4$ & $-12.4 \pm 31.2$ & $-4.6(-14.8,5.5)$ \\
\hline & Genital prolapse & $-41.5 \pm 31.8$ & $-41.9 \pm 37.3$ & $-0.4(-12.7,11.9)$ \\
\hline \multicolumn{5}{|c|}{ Mean change in DDI domain scores } \\
\hline \multirow[t]{5}{*}{ DDI } & Constipation & $-0.3 \pm 17.8$ & $-2.4 \pm 16.8$ & $-2.1(-8.4,4.2)$ \\
\hline & Obstructive defecation & $2.1 \pm 18.4$ & $-5.2 \pm 19.1$ & $-7.3(-14.2,0.5)$ \\
\hline & Pain & $-5.8 \pm 17.6$ & $-0.8 \pm 19.6$ & $5.0(-1.5,11.7)$ \\
\hline & Fecal incontinence & $4.5 \pm 20.5$ & $1.3 \pm 26.5$ & $-3.2(-11.7,5.3)$ \\
\hline & Flatus & $2.2 \pm 37.8$ & $2.0 \pm 36.0$ & $-0.2(-13.2,12.8)$ \\
\hline \multicolumn{5}{|c|}{ Mean change in IIQ scores } \\
\hline \multirow[t]{5}{*}{ IIQ } & Physical & $-10.6 \pm 26.4$ & $-13.5 \pm 26.4$ & $-2.9(-12.4,6.5)$ \\
\hline & Mobility & $-5.6 \pm 24.3$ & $-9.3 \pm 22.9$ & $-3.7(-11.8,4.6)$ \\
\hline & Social & $-5.0 \pm 19.6$ & $-8.4 \pm 22.6$ & $-3.4(-11.2,4.6)$ \\
\hline & Embarrassment & $-0.9 \pm 20.6$ & $-0.5 \pm 23.4$ & $0.4(-7.6,8.4)$ \\
\hline & Emotional & $-3.6 \pm 25.4$ & $-4.8 \pm 24.3$ & $-1.2(-10.0,7.6)$ \\
\hline \multicolumn{2}{|c|}{ Mean change in PISQ-12 scores } & $0.0 \pm 4.2$ & $2.9 \pm 6.8$ & $-2.9(-6.8,1.1)$ \\
\hline
\end{tabular}

Data presented as mean (domain baseline scores minus corresponding 7-year domain scores) \pm standard deviation (SD). Negative scores in change reflect reduction in bother and improved quality of life compared with baseline $U D I$ Urogenital Distress Inventory, DDI Defecatory Distress Inventory, IIQ Incontinence Impact Questionnaire $(0-00), P I S Q-12$ Prolapse and Incontinence Sexual Questionnaire short form (positive change from baseline indicates better sexual function). 


\section{Appendix 3}

Table 7 Results per vaginal compartment at 7 years
Results per vaginal compartment

\begin{tabular}{|c|c|c|c|}
\hline Anterior compartment (level II treatment) & Anterior mesh & Anterior colporrhaphy & \\
\hline Reoperation POP anterior compartment & $0 / 32(0)$ & $3 / 39(8)$ & $-8(-16,1)$ \\
\hline $\mathrm{POP} \geq$ stage II anterior compartment & $8 / 32(25)$ & $25 / 39(64)$ & $-39 *(-60,-18)$ \\
\hline Reoperation POP and/or POP $\geq$ stage II & $8 / 32(25)$ & $27 / 39(69)$ & $-44 *(-65,-23)$ \\
\hline POP $>$ hymen anterior compartment & $3 / 32(9)$ & $8 / 39(20)$ & $-11(-27,5)$ \\
\hline Reoperation POP and/or POP $>$ hymen & $3 / 32(9)$ & $11 / 39(28)$ & $-19 *(-36,-2)$ \\
\hline \multicolumn{4}{|l|}{ Composite success } \\
\hline - Anterior mesh only (level II) & $14 / 24(58)$ & & \\
\hline - Anterior \& total mesh (level II + I) & $22 / 35(63)$ & $18 / 40(45)$ & $18(-4,40)$ \\
\hline Apical compartment (level I treatment) & Apical mesh & Native tissue & \\
\hline Reoperation for POP apical compartment & $0 / 11(0)$ & $3 / 34(9)$ & $-9 *(-11,-4)$ \\
\hline $\mathrm{POP} \geq$ II apical compartment & $1 / 11(9)$ & $1 / 34(3)$ & $6(-12,24)$ \\
\hline Reoperation POP and/or POP-Q $\geq$ II & $1 / 11(9)$ & $4 / 34(12)$ & $-3(-23,18)$ \\
\hline POP apical compartment $>$ hymen & $1 / 11(9)$ & $1 / 34(3)$ & $6(-12,24)$ \\
\hline Reoperation POP and/or POP > hymen & $1 / 11(9)$ & $3 / 34(9)$ & $0(-19,20)$ \\
\hline Composite success & 8/11 (73) & $16 / 36(44)$ & $29(-3,60)$ \\
\hline Posterior compartment (level II treatment) & Mesh & Colporrhaphy & \\
\hline Reoperation POP posterior compartment & $1 / 32(3)$ & $5 / 45(11)$ & $-8(-19,3)$ \\
\hline $\mathrm{POP} \geq$ II posterior compartment & $4 / 32(12)$ & $13 / 43(30)$ & $-18(-36,0)$ \\
\hline Reoperation POP and/or POP-Q $\geq$ II & $4 / 32(12)$ & $18 / 45(40)$ & $-28 *(-46,-9)$ \\
\hline POP posterior compartment $>$ hymen & $1 / 32(3)$ & $1 / 43(2)$ & $1(-7,8)$ \\
\hline Reoperation POP and/or POP $>$ hymen & $2 / 32(6)$ & $6 / 45(13)$ & $-7(-20,6)$ \\
\hline \multicolumn{4}{|l|}{ Composite success } \\
\hline - Posterior mesh only (level II) & $9 / 23(39)$ & & \\
\hline - Posterior and total mesh (level II + I) & $17 / 34(50)$ & $25 / 45(56)$ & $-6(-28,17)$ \\
\hline
\end{tabular}

Data presented as $n(\%), n(\%, 95 \% \mathrm{CI})$, or $\%(95 \% \mathrm{CI})$

$P O P$ pelvic organ prolapse

*This difference would be statistically significant if tested at a significance level of 0.05 


\section{Appendix 4}

Table 8 Adverse events at 7 years

\begin{tabular}{|c|c|c|c|}
\hline & Mesh & Native tissue & Risk difference $(95 \% \mathrm{CI})$ \\
\hline De novo SUI & $12 / 62(19)$ & $8 / 66(12)$ & $7(-5,20)$ \\
\hline \multicolumn{4}{|l|}{ Graft-related adverse events ${ }^{\mathrm{a}}$} \\
\hline - Exposure & $22 / 53(42)$ & $4 / 67(6)^{b}$ & $36^{*}(21,50)$ \\
\hline - Retraction mesh during examination & $17 / 53(32)$ & $2 / 67(3)$ & $29 *(16,42)$ \\
\hline - Reoperation for complication & $8 / 53(15)$ & $4 / 68(6)$ & $9(-2,20)$ \\
\hline - Reoperation for exposure & $7 / 53(13)$ & $0 / 68(0)$ & $13^{*}(4,22)$ \\
\hline \multicolumn{4}{|l|}{ Pain and dyspareunia } \\
\hline \multicolumn{4}{|l|}{ Indicated at the outpatient visit } \\
\hline Pain & $8(15)$ & $20(30)$ & $-15(-30,0)$ \\
\hline Dyspareunia & $14(26)$ & $15(22)$ & $4(-12,20)$ \\
\hline Pain and/or dyspareunia & $17(32)$ & $29(43)$ & $-11(-28,6)$ \\
\hline \multicolumn{4}{|l|}{ Location of pain } \\
\hline - Vulvar & $1(6)$ & $2(7)$ & $-1(-16,14)$ \\
\hline - Vaginal & $1(6)$ & $5(17)$ & $-11(-29,6)$ \\
\hline - Lower abdomen & $4(24)$ & $8(28)$ & $-4(-30,22)$ \\
\hline - Lower back & $0(0)$ & $4(14)$ & $-14(-26,0)$ \\
\hline - Other & $11(65)$ & $10(34)$ & $29 *(2,59)$ \\
\hline VAS (spontaneous pain) & $1.4 \pm 2.3$ & $2.0 \pm 2.3$ & $-0.6(-2.0,0.8)$ \\
\hline VAS (during physical activity) & $2.0 \pm 3.1$ & $2.3 \pm 2.5$ & $-0.3(-2.0,1.4)$ \\
\hline VAS (during sexual intercourse) & $4.6 \pm 3.6$ & $2.7 \pm 3.3$ & $1.9(-0.2,4.0)$ \\
\hline \multicolumn{4}{|l|}{ During gynecological examination } \\
\hline Provoked pain & $24(45)$ & $16(24)$ & $21 *(5,38)$ \\
\hline - Apical & $12(50)$ & $11(69)$ & $-19(-49,12)$ \\
\hline - Mesh arms (distal/proximal) & $8(33)$ & $2(12)$ & $21(-4,46)$ \\
\hline - Deep ligament & $1(4)$ & $1(6)$ & $-2(-16,12)$ \\
\hline - Other & $3(12)$ & $2(12)$ & $0(-21,21)$ \\
\hline VAS (patient) & $5.2 \pm 2.1$ & $5.3 \pm 2.2$ & $-0.1(-1.5,1.3)$ \\
\hline VAS (subjective impression of examiner) & $5.3 \pm 2.2$ & $4.8 \pm 2.1$ & $0.5(-0.9,1.9)$ \\
\hline \multicolumn{4}{|l|}{ Indicated on questionnaire } \\
\hline Dyspareunia during sexual intercourse & $13 / 64(20)$ & $12 / 72(17)$ & $3(-9,17)$ \\
\hline - Somewhat & $5(38)$ & $6(50)$ & $-12(-50,27)$ \\
\hline - Moderately & $4(31)$ & $4(33)$ & $-2(-39,34)$ \\
\hline - Quite a bit & $4(31)$ & $2(17)$ & $14(-19,47)$ \\
\hline
\end{tabular}

Data presented as numbers $(\%)$ or mean \pm standard deviation $(\mathrm{SD})$ and mean $(95 \% \mathrm{CI})$

$S U I$ stress urinary incontinence, VAS visual analog scale, $C I$ confidence interval

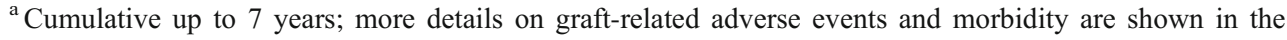
"Addendum"

${ }^{\mathrm{b}}$ Exposure of Prolene thread in sacrospinous ligament fixation (1), exposure after midurethral sling for incontinence (1), exposures of mesh inserted for POP recurrence after index surgery (2)

*This difference would be statistically significant if tested at a significance level of 0.05 
Open Access This article is distributed under the terms of the Creative Commons Attribution 4.0 International License (http:// creativecommons.org/licenses/by/4.0/), which permits unrestricted use, distribution, and reproduction in any medium, provided you give appropriate credit to the original author(s) and the source, provide a link to the Creative Commons license, and indicate if changes were made.

\section{References}

1. Denman MA, Gregory WT, Boyles SH, Smith V, Edwards SR, Clark AL. Reoperation 10 years after surgically managed pelvic organ prolapse and urinary incontinence. Am J Obstet Gynecol. 2008;198:555. e1-5

2. Scott NW, McCormack K, Graham P, Go PM, Ross SJ, Grant AM (2002). Open mesh versus nonmesh for repair of femoral and inguinal hernia. Cochrane database Syst rev :CD002197.

3. Bezerra CA, Bruschini H (2001). Suburethral sling operations for urinary incontinence in women. Cochrane Database Syst Rev: CD001754.

4. Debodinance $\mathrm{P}$, Berrocal J, Clave H, et al. Changing attitudes on the surgical treatment of urogenital prolapse: birth of the tension-free vaginal mesh. J Gynecol Obstet Biol Reprod (Paris). 2004;33:577_88.

5. Fatton B, Amblard J, Debodinance P, Cosson M, Jacquetin B. Transvaginal repair of genital prolapse: preliminary results of a new tension-free vaginal mesh (Prolift technique)-a case series multicentric study. Int Urogynecol J Pelvic Floor Dysfunct. 2007;18:743-52.

6. UPDATE on Serious Complications Associated with Transvaginal Placement of Surgical Mesh for Pelvic Organ Prolapse: FDA Safety Communication. July 13, 2011. (at: http://www.fda.gov/ MedicalDevices/Safety/AlertsandNotices/ucm262435.htm).

7. Maher C, Feiner B, Baessler K, Christmann-Schmid C, Haya N, Marjoribanks J. Transvaginal mesh or grafts compared with native tissue repair for vaginal prolapse. Cochrane Database Syst Rev. 2016;2:CD012079.

8. Withagen MI, Milani AL, den Boon J, Vervest HA, Vierhout ME. Trocar-guided mesh compared with conventional vaginal repair in recurrent prolapse: a randomized controlled trial. Obstet Gynecol. 2011;117:242-50.

9. Srikrishna S, Robinson D, Cardozo L. Validation of the patient global impression of improvement (PGI-I) for urogenital prolapse. Int Urogynecol J. 2010;21:523-8.

10. EuroQol G. EuroQol-a new facility for the measurement of healthrelated quality of life. Health Policy. 1990;16:199-208.

11. van der Vaart CH, de Leeuw JR, Roovers JP, Heintz AP. Measuring health-related quality of life in women with urogenital dysfunction: the urogenital distress inventory and incontinence impact questionnaire revisited. Neurourol Urodyn. 2003;22:97-104.

12. LA t H, Utomo E, Steensma AB, Blok BF, Korfage IJ. x. Int Urogynecol J. 2015;26:1293-303.

13. Rogers RG, Coates KW, Kammerer-Doak D, Khalsa S, Qualls C. A short form of the pelvic organ prolapse/urinary incontinence sexual questionnaire (PISQ-12). Int Urogynecol J Pelvic Floor Dysfunct. 2003; 14:164-8.

14. Haylen BT, Maher CF, Barber MD, et al. An international Urogynecological association (IUGA) / international continence society (ICS) joint report on the terminology for female pelvic organ prolapse (POP). Neurourol Urodyn. 2016;35:137-68.
15. Haylen BT, Freeman RM, Lee J, et al. An international Urogynecological association (IUGA)/international continence society (ICS) joint terminology and classification of the complications related to native tissue female pelvic floor surgery. Int Urogynecol J. 2012;23:515-26.

16. Barber MD, Brubaker L, Nygaard I, et al. Defining success after surgery for pelvic organ prolapse. Obstet Gynecol. 2009;114:600 9.

17. Hodges JL, Lehmann EL. Estimation of location based on ranks. Ann Math Stat. 1963;34(2):598-611.

18. Withagen MI, Vierhout ME, Milani AL. Does trocar-guided tension-free vaginal mesh (Prolift) repair provoke prolapse of the unaffected compartments? Int Urogynecol J. 2010;21:271-8.

19. Withagen MI, Milani AL, de Leeuw JW, Vierhout ME. Development of de novo prolapse in untreated vaginal compartments after prolapse repair with and without mesh: a secondary analysis of a randomised controlled trial. Br J Obstet Gynaecol. 2012;119:354-60.

20. Jacquetin B, Hinoul P, Gauld J, et al. Total transvaginal mesh (TVM) technique for treatment of pelvic organ prolapse: a 5-year prospective follow-up study. Int Urogynecol J. 2013;24:1679-86.

21. Withagen MI, Vierhout ME, Hendriks JC, Kluivers KB, Milani AL. Risk factors for exposure, pain, and dyspareunia after tension-free vaginal mesh procedure. Obstet Gynecol. 2011;118:629-36.

22. Nygaard I, Brubaker L, Zyczynski HM, et al. Long-term outcomes following abdominal sacrocolpopexy for pelvic organ prolapse. JAMA. 2013;309:2016-24.

23. Toozs-Hobson P, Freeman R, Barber M, et al. An international Urogynecological association (IUGA)/international continence society (ICS) joint report on the terminology for reporting outcomes of surgical procedures for pelvic organ prolapse. Int Urogynecol J. 2012;23:527-35.

24. Wu PY, Chang CH, Shen MR, Chou CY, Yang YC, Huang YF. Seeking new surgical predictors of mesh exposure after transvaginal mesh repair. Int Urogynecol J. 2016;27(10):1547-55.

25. Kelly M, Macdougall K, Olabisi O, McGuire N. (2016). In vivo response to polypropylene following implantation in animal models: a review of biocompatibility. Int Urogynecol J. 2017;28(2):171-80.

26. Chughtai B, Barber MD, Mao J, Forde JC, Normand ST, Sedrakyan A. (2016). Association between the amount of vaginal mesh used with mesh erosions and repeated surgery after repairing pelvic organ prolapse and stress urinary incontinence. JAMA Surg. 2017;152(3):257-63.

27. Shull BL. Reasonable people disagree: lessons learned from the sling and mesh story. Int Urogynecol J. 2016;27:1289-91.

28. Donders ART, van der Heijden GJ, Stijnen T, Moons KG. A gentle introduction to imputation of missing values. J Clin Epidemiol. 2006;59(10):1087-91.

29. American College of Obstetricians and Gynecologists, Committee Opinion, Committee on Ethics. Innovative practice: ethical guidelines. Obstet Gynecol. 2006;195:1762-71.

30. Vergeldt TF, van Kuijk SM, Notten KJ, Kluivers KB, Weemhoff M. Anatomical cystocele recurrence: development and internal validation of a prediction model. Obstet Gynecol. 2016;127:341-7.

31. Chapple CR, Cruz F, Deffieux X, et al. (2017). Consensus statement of the European urology association and the European Urogynaecological association on the use of implanted materials for treating pelvic organ prolapse and stress urinary incontinence. Eur Urol. 2017;72(3):424-31. 